\title{
O ESPÓLIO CIENTÍFICO DO PROFESSOR ORLANDO RIBEIRO*
}

SUZANNE DAVEAU ${ }^{1}$

\section{O LEGADO CIENTÍFICO DE ORLANDO RIBEIRO}

Do então designado Instituto para Alta Cultura, Orlando Ribeiro obteve aprovação para a fundação de um Centro de Estudos Geográficos, em Lisboa, em 1943. Concebeu desde logo este organismo como uma instituição de trabalho aberta a todos os que desejavam investigar em Geografia, fossem eles geógrafos diplomados ou não, portugueses ou estrangeiros. Durante os três decénios em que foi Director do Centro, Orlando Ribeiro aplicou esta regra de larga abertura, atraindo todos os investigadores que lhe pareciam capazes de enriquecer, de qualquer modo, o conhecimento do país, colocando à sua disposição toda a documentação científica que ia acumulando.

Considerava a própria casa uma espécie de anexo do "Centro" e a documentação ali guardada destinada a voltar para este, depois de utilizada nas investigações em curso. Desde o princípio, as suas excelentes fotografias foram armazenadas e catalogadas na incipiente Fototeca do Centro, onde, ainda actualmente, constituem a colecção mais rica e notável deste arquivo. Foi este serviço que recolheu recentemente a valiosa colecção de bilhetes-postais ilustrados, acumulada por Orlando Ribeiro ao longo da sua vida, onde se encontram já cuidadosamente classificados e arquivados ${ }^{2}$. Do mesmo modo, os mapas adquiridos por ele estão conservados e são geridos pela respectiva Mapoteca, bem como, parte dos seus livros e revistas, que desde há muitos anos enriquecem não só a Biblioteca do Centro, mas também a Biblioteca do Instituto de Geografia da Faculdade de Letras do Porto, onde se constituíram como um dos núcleos iniciais de documentação da então incipiente biblioteca.

Os livros, revistas e folhetos de uso mais corrente ficaram, no entanto, na nossa casa, tendo transitado, em 1966, da Travessa do Monte do Carmo, em Lis-

* Recebido: 17/01/2008. Revisto: 1/03/2008. Aceite: 10/04/2008.

1 Investigadora do Centro de Estudos Geográficos da Universidade de Lisboa.

E-mail: sdaveau@clix.pt

2 Ver a seguir a notícia de Mário Neves e Rute Vieira. 
boa, para a mais vasta casa campestre de Vale de Lobos. Mas Orlando Ribeiro teve o cuidado, já em 1964-65, de mandar organizar um ficheiro detalhado e numerado das espécies que possuía a um dos funcionários do Centro, António Miguel Agostinho, para facilitar a sua futura inserção na respectiva Biblioteca. Se este ficheiro não foi utilizado quando se realizou a catalogação geral da Biblioteca Científica Pessoal, foi porque a metodologia e as técnicas de catalogação sofreram, entretanto, profundas modificações. No entanto ele continua a ser um instrumento precioso para reconstituir as fases de constituição da dita Biblioteca.

Em 1983, sentindo a saúde cada vez mais abalada, e diminuída a sua capacidade de trabalho, Orlando Ribeiro quis assegurar legalmente o destino do seu Espólio Científico, redigindo um testamento, no qual esmiuçou as disposições que lhe pareciam então as mais apropriadas. Encarregou o filho mais velho, o geólogo António Ribeiro, e eu própria, de cumprir as suas vontades testamentárias. Dez anos decorridos depois da sua morte em Novembro de 1997, o essencial do laborioso tratamento deste imponente legado encontra-se concluído. Torna-se possível difundir o balanço do seu conteúdo e do tratamento que lhe foi dado, bem como indicar os modos de acesso que irão permitir, de futuro, o seu aproveitamento.

\section{O TRATAMENTO PRÉVIO DO ESPÓLIO CIENTÍFICO}

Em meados do decénio consagrado ao inventário e à arrumação do legado, publicou-se na Finisterra n. ${ }^{\circ}$ 73, com autoria de S. Daveau, M. J. Feijão e P. J. S. Barata, um primeiro balanço do tratamento então em curso. Remete-se o leitor interessado para este artigo, onde encontrará um extracto do testamento de 1983, uma estimativa prévia do conteúdo do Espólio e as normas adoptadas para o seu tratamento. A realização do complexo projecto tornou-se possível através de importantes subsídios, sucessivamente concedidos pela Fundação para a Ciência e a Tecnologia e pela Fundação Calouste Gulbenkian. O tratamento realizou-se, também, graças à ajuda, financeira e prática, do próprio Centro de Estudos Geográficos de Lisboa, destinatário do legado. Não se pode esquecer, igualmente, a grande e generosa ajuda prestada por diversos membros da família e alguns amigos e colegas, nem a dedicação dos bibliotecários de várias categorias e especialidades, que participaram tecnicamente no projecto, trabalhando com eficiência, em condições materiais muitas vezes difíceis. Foi de importância fundamental a constante e amiga colaboração de Maria Joaquina Feijão, bibliotecária responsável da Área de Cartografia da Biblioteca Nacional de Portugal, que concebeu e regeu, com a maior competência e dedicação, a parte conceptual e logística do tratamento da Biblioteca Científica Pessoal. Sem ela, a preservação deste importante tesouro patrimonial não teria sido possível.

Não posso deixar de lembrar também, e muito em especial, o filho Manuel Ramos Ribeiro, excelente filólogo e latinista, a quem se deve a primeira e sábia arrumação de um arquivo caseiro bastante caótico, que se foi acumulando durante 
meio século, numa desordem persistente. Sem o seu saber e a sua amorosa e filial paciência, não se teriam recuperado parte dos manuscritos e da correspondência. Pouco tempo antes de morrer de cruel doença, em Outubro de 2004, preocupava-se ainda por não ter completamente acabado a arrumação de alguns dos elementos do Espólio. Também teve morte muito prematura, em Janeiro de 2007, a jovem e brilhante geógrafa-bibliotecária Anabela Nunes, que realizou com cuidado a classificação CDU de toda a Biblioteca Científica.

Em 2004, o tratamento do Espólio Científico de Orlando Ribeiro pareceu-nos já suficientemente adiantado para tornar possível a difusão de parte dos resultados obtidos.

Escolheu-se criar um Sitio Internet (www.orlando-ribeiro.info), por parecer o melhor modo de colocar a tecnologia usada à prova das reacções do público. Além do Catálogo online da parte já catalogada da biblioteca (cerca de 8500 espécies), a primeira versão do Sítio oferecia a bibliografia das obras do autor, bem como outros dados biográficos e bibliográficos, belamente ilustrados por fotografias (fig. 1). As organizadoras beneficiaram, na altura, do saber, bom gosto e entusiasmo de Inês Cordeiro, então bibliotecária da Fundação Calouste Gulbenkian. A excepcional qualidade funcional e estética deste Sítio, logo apreciada pelos numerosos utilizadores, é-lhe, em grande parte, devida.

A divulgação parcial e provisória do Espólio foi anunciada primeiro por um poster de Suzanne Daveau, afixado durante uma Exposição organizada pelo Centro de Estudos Geográficos de Lisboa, nas instalações da Faculdade de Letras, durante a Quinzena da Geografia de Janeiro de 2004. Seguiu-se uma nota na Finisterra n. ${ }^{\circ} 78$ e, finalmente, um colóquio realizado em 27 de Novembro de 2004, na Biblioteca Municipal Orlando Ribeiro de Telheiras. Esta conferência foi dirigida, em francês, ao público internacional que participou no Colóquio Silva Telles. 100 Anos de Ensino Superior de Geografia em Portugal (1904-2004), organizado pela Associação Portuguesa de Geógrafos e pela Sociedade de Geografia de Lisboa.

\section{O SÍTIO INTERNET ORLANDO RIBEIRO}

A nova edição que ficará acessível através do endereço electrónico do CEG http://www.ceg.pt, traz como principais novidades, o catálogo completo da Biblioteca Científica Pessoal (13 324 espécies) e a revisão geral de três listas, a dos Cadernos de campo e as Bibliografias de Orlando Ribeiro e dos textos referentes à sua obra. Mas a organização da primeira edição foi exactamente mantida. Apresenta-se a seguir o conteúdo das principais rubricas do Sítio.

A Personalidade do geógrafo é primeiro sucintamente caracterizada, na sua qualidade de renovador da Geografia em Portugal.

Ampla e clara Bio-bibliografia situa, a seguir, a sua produção científica, em função de cinco períodos: de 1911 a 1928, Infância e Juventude, de 1929 a 1936, Formação Universitária, de 1937 a 1950, Paris e Congresso Internacional de 
Geografia, de 1951 a 1980, Professor e Investigador, de 1981 a 1997, Reconhecimento e Retiro.

Aparece depois a Bibliografia científica de Orlando Ribeiro, numa versão cuidadosamente revista e completada, a partir das edições anteriores de I. do Amaral e A. Amaral, em 1981, e de S. Daveau, em 1998. Comporta 413 obras, numeradas por ano de publicação e assinalando-se as várias edições. Todas as obras são providas de uma breve e significativa análise de conteúdo, devida a Ilídio do Amaral. Esta Bibliografia pode ser facilmente consultada de modo analítico, por estar também incluída na Biblioteca Científica Pessoal, última rubrica do Sítio. Bastará chamar ali "Orlando Ribeiro" na qualidade de autor, e procurar ao mesmo tempo qualquer outra palavra, de natureza locativa ou temática.

Aparece, a seguir, uma lista de publicações sobre a Vida e Obra de Orlando Ribeiro, ou seja, o que se costuma chamar "Bibliografia passiva". Largamente ampliada na actual edição e arrumada por datas, a lista comporta sem dúvida ainda algumas lacunas.

A rubrica seguinte evoca as Viagens do geógrafo, através de abundante selecção de fotografias da sua autoria, de grande qualidade artística e documental. A escolha foi baseada na exposição Além-Mar. Viagens de Orlando Ribeiro, organizada por Mário Neves, em 2002. Esta fonte documental intermédia explica que apareça apenas uma parte dos espaços percorridos por Orlando Ribeiro: Açores, Madeira, Cabo Verde, Guiné, S. Tomé e Príncipe, Angola, Moçambique, Goa, Damão e Diu. Para consultar as não menos numerosas fotografias de Portugal, Espanha e outros países europeus ou mediterrâneos, bem como as do Brasil e outros países americanos, é preciso utilizar o ficheiro da Fototeca do Centro. Lembra-se que o significado das fotografias ganhará, quase sempre, se for completado pela consulta do correspondente Caderno de Campo.

Aparece a seguir a lista destes 63 Cadernos de Campo, recentemente completada pela descoberta de alguns, que tinham ficado misturados entre documentos manuscritos ainda não classificados. Os títulos que lhes foram dados indicam os países ou regiões descritos neles. Os preciosos Cadernos deverão ser conservados no Arquivo de Cultura Portuguesa Contemporânea da Biblioteca Nacional de Portugal.

Orlando Ribeiro fotógrafo é o título da rubrica seguinte do Sítio. A parte fotográfica da sua obra encontra-se evocada através do uso que ele fez delas, nas próprias publicações e através das exposições que se multiplicaram a partir de 1994, quando se editou o catálogo Finisterra, no quadro dos Encontros de Fotografia de Coimbra.

Finalmente, aparece no Sítio o conjunto documental mais vultuoso: o catálogo da Biblioteca Cientifica Pessoal de Orlando Ribeiro, realizado pela técnica especialista de biblioteca e documentação Joaquina David, com uma competência e dedicação fora do vulgar, segundo a metodologia estabelecida por Maria Joaquina Feijão e explicitada no Sítio. 

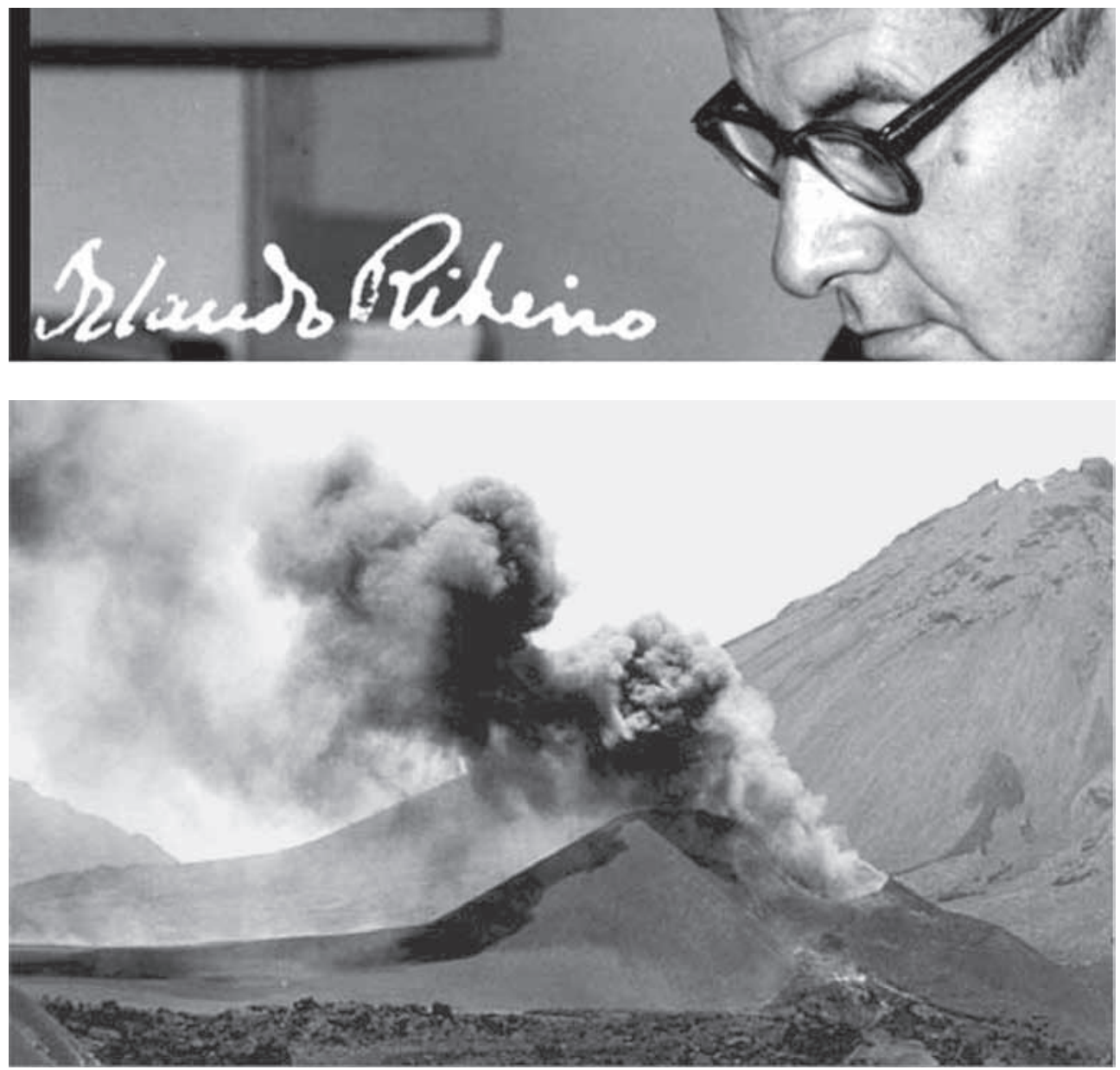

Fig. 1 - As imagens de entrada do sítio www.orlando-ribeiro.info Fig. 1 - The introductory page of Orlando Ribeiro web site

As primeiras compras de livros pelo jovem estudante Orlando Ribeiro datam de 1929 (fig. 2). A partir de 1965, a Biblioteca cresceu também através das aquisições de Suzanne Daveau, trazidas de França nesta altura, ou posteriores. A catalogação foi concluída com as obras adquiridas até 2004. Esta Biblioteca encontra-se actualmente em vias de instalação nas dependências da Biblioteca da Faculdade de Letras da Universidade de Lisboa.

O catálogo distingue três conjuntos. As obras, cuja cota começa por ORC, estavam arrumadas na "cave" da casa de Vale de Lobos, foram já divulgadas na primeira edição do Sítio, e incluem a grande maioria das "separatas". As cotas que começam por OR correspondem às obras catalogadas posteriormente, que se encontravam na entrada da casa ou no escritório, e que vão estar em breve 
disponíveis, na instalação definitiva. As cotas que começam por OR/SD assinalam as obras ainda conservadas na nossa casa de Vale de Lobos, segundo estava previsto no testamento de 1983, por me serem frequentemente úteis para investigações em curso.

Considero a actual edição do Sítio como a apresentação definitiva do tratamento que foi dado ao Espólio Científico legado por Orlando Ribeiro. No entanto, é de esperar que ele seja futuramente completado pela indicação de novas publicações sobre a vida e a obra do geógrafo, bem como pela descoberta de mais cartas ou manuscritos dele, que existem provavelmente em diversos arquivos, ainda não explorados ou abertos.

\section{MODALIDADES DE CONSERVAÇÃO E DE CONSULTA DO ESPÓLIO}

Em finais de 2005, já se encontrava realizado o essencial da catalogação do material constituinte do Espólio Científico de Orlando Ribeiro. Tornou-se então urgente tomar decisões definitivas relativas ao seu destino, decisões até lá adiadas, por ultrapassarem o âmbito da minha própria vontade. Onde instalar o material devidamente repertoriado, para lhe assegurar, simultaneamente, boas condições de conservação e de acesso? Quais as melhores regras de consulta e utilização?

Com a passagem do tempo, o testamento de 1983 tinha-se tornado em boa parte inaplicável. Orlando Ribeiro não imaginou, quando o redigiu, nem a dimensão física do Espólio, nem a complexidade da sua gestão. A sua ideia tinha sido transformar o seu antigo gabinete de trabalho do Centro em sala de arquivo e de consulta. E pensou, com certeza, que a gestão do arquivo seria facilmente assegurada, como tantas outras tarefas, pelo eficiente e devotado secretário do Centro, Dr. Machado Guerreiro. A ideia de instalar o Espólio no próprio gabinete tinha germinado em 1978, quando visitámos, em companhia de Bodo Freund, a Universidade de Bonn, onde tinha ensinado o colega e amigo Carl Troll. A biblioteca legada por este estava, com efeito, instalada no seu antigo gabinete e numa sala anexa.

Mas a dimensão da nossa Biblioteca cientifica (fig. 3) tornava inexequível esta ideia inicial. Outra solução, surgida então em alternativa, foi anexá-la ou integrá-la na Biblioteca do Centro, a qual esteve instalada durante anos numa das suas salas, de início usada como local de aulas e de colóquios (fig. 4). Mas o crescimento desta Biblioteca colectiva obrigou, em breve, a colocar parte das colecções em arrecadações afastadas e a empurrar as mesas de consulta dos alunos para o corredor de circulação da Faculdade, em local incómodo e inseguro. Em 2000 abriram finalmente as novas e amplas instalações destinadas à Biblioteca da Faculdade de Letras da Universidade de Lisboa. Os responsáveis do Centro de Estudos Geográficos decidiram aproveitar os novos espaços para colocar em condições fisicamente melhores a Biblioteca do Centro. Se esta transferência facilitou bastante a utilização corrente dos livros pelos alunos e investigadores, 


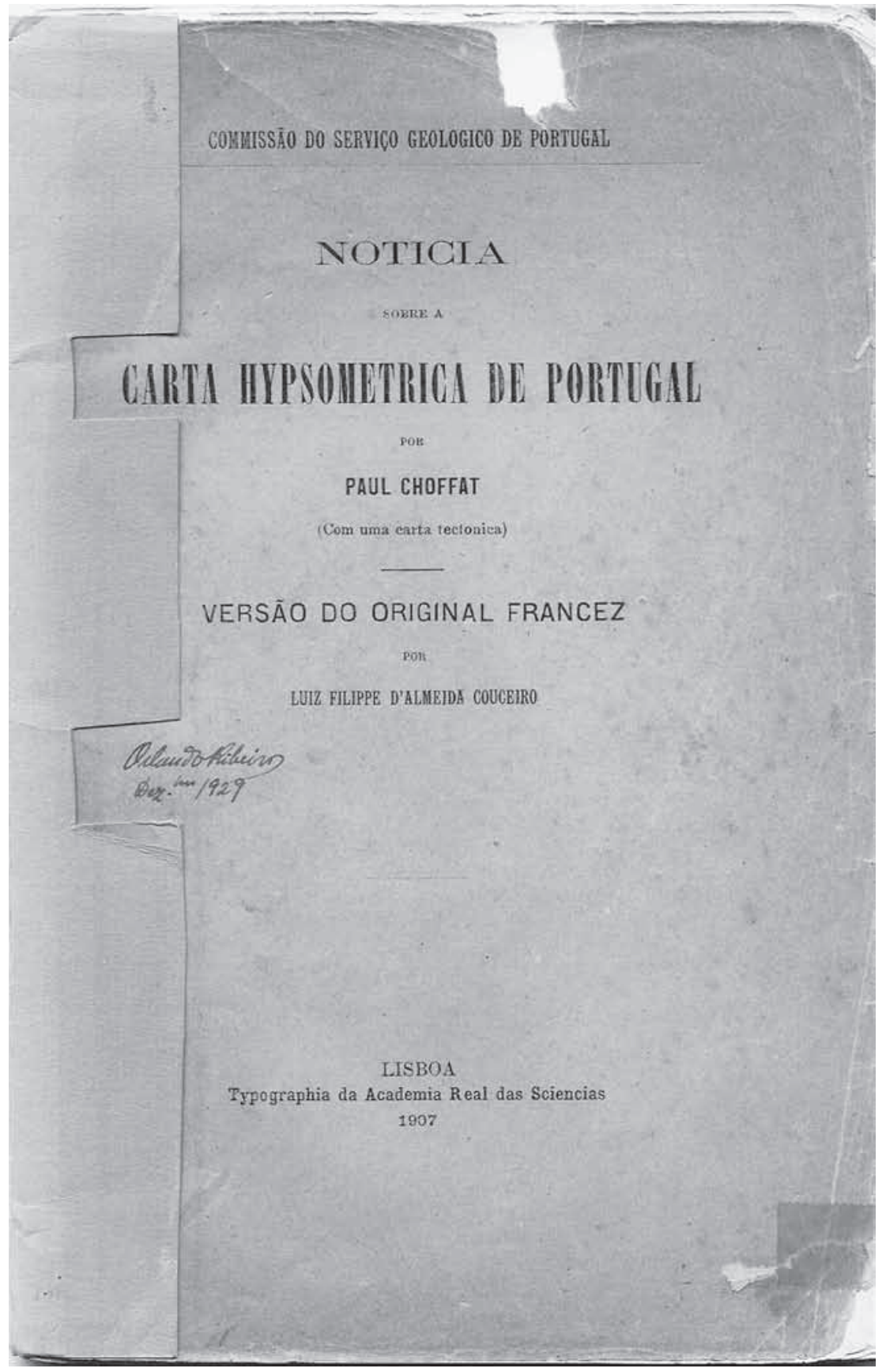

Fig. 2 - Um dos primeiros livros científicos comprados por Orlando Ribeiro, em Dezembro de 1929.

Fig. 2 - One of the first scientific books bought by Orlando Ribeiro. 
teve consequências menos felizes, que tornaram irrealizável a inserção da Biblioteca pessoal de Orlando Ribeiro.

Concebida em regime de livre acesso, a nova instalação não devia sequer ter recebido as obras mais valiosas ou frágeis da Biblioteca do Centro, e está ainda menos adaptada à conservação e gestão de um conjunto documental, válido sobretudo pelo significado da sua elaboração e do seu uso. A primeira é legível através da indicação das datas de aquisição, oferta e dedicatória. O uso transparece nas numerosas anotações nas margens de livros e artigos, e nos inúmeros verbetes de leitura, com anotações abreviadas e alfabetados, que permitiam a Orlando Ribeiro reencontrar com facilidade, pormenores úteis das suas antigas leituras. A catalogação da Biblioteca pessoal foi concebida para preservar o mais

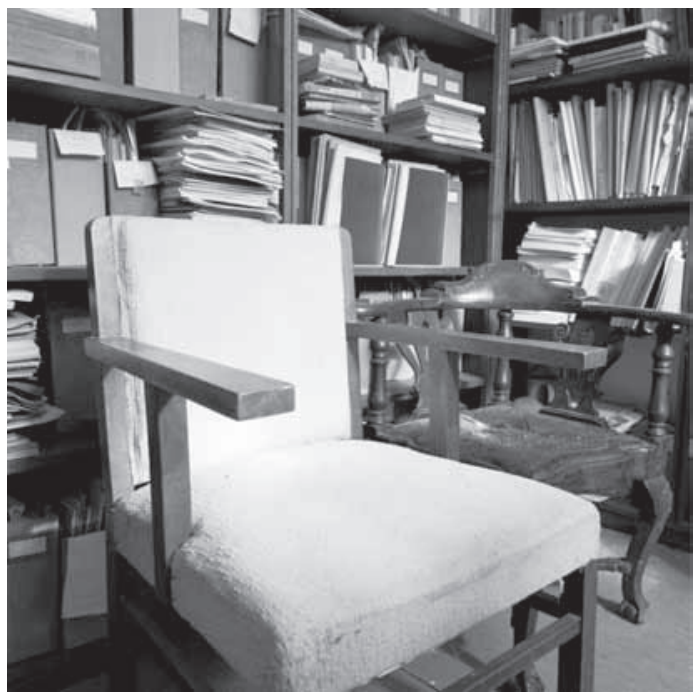

Fig. 3 - Uma parte da Biblioteca pessoal, acumulada na cave da casa de Vale de Lobos.

Fig. 3 - Part of Orlando Ribeiro private library in his Vale de Lobos house.

possível, através do sistema de cotação, a arrumação original, testemunho directo da sua passada funcionalidade, conforme aparece explicado em pormenor no Sítio. Não era aceitável ver destruído, de repente, este valioso e trabalhoso tratamento, pela inserção cega num conjunto já deteriorado, incapaz de assegurar a sua gestão e preservação.

Foi apenas muito recentemente, em Dezembro de 2007, que se encontrou uma solução viável, através da decisão de instalar os espólios científicos dos antigos Professores da Faculdade em salas próprias, inseridas no edifício da Biblioteca principal da Faculdade de Letras, mas com normas de gestão e de consulta apropriadas. Para ter acesso às obras cotadas ORC ou OR, dirigir o pedido ao Chefe de Divisão da Biblioteca (bib.biblio@fl.ul.pt). Os registos com estas cotas vão ficar em breve incorporadas no SIBUL, catálogo colectivo das Biblio- 


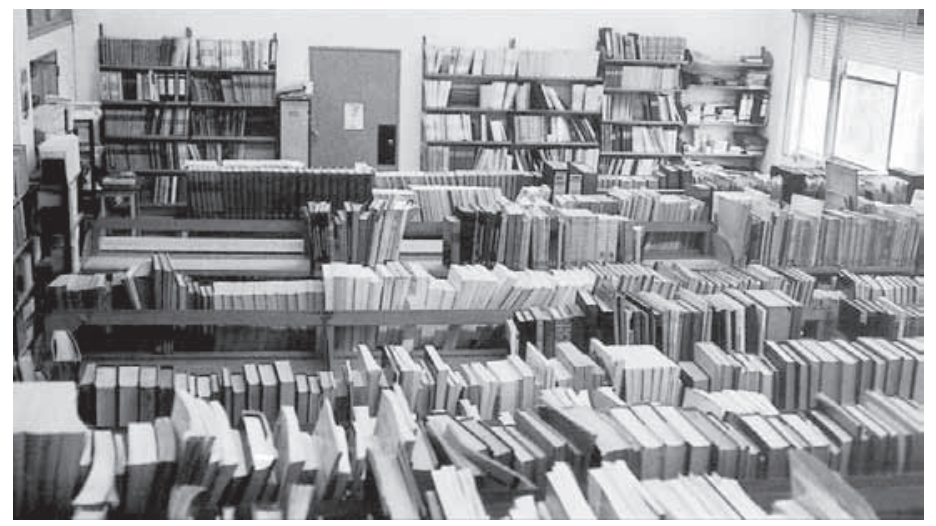

Fig. 4 - Nos anos 70, o crescimento da Biblioteca do CEG já tinha obrigado a instalar as mesas de leitura no corredor da Faculdade.

Fig. 4 - The CEG library in the 1970s.

tecas da Universidade de Lisboa. Parece assim resolvido, de modo definitivo, o destino do elemento mais volumoso do Espólio. As obras cotadas OR/SD podem ser por agora consultadas através de pedido dirigido a sdaveau@clix.pt.

Foi já dito que soluções bastante satisfatórias existem para as fotografias e mapas, geridos respectivamente pela Fototeca e pela Mapoteca do Centro. Seria de desejar que estes serviços, gestores de patrimónios de tão elevado valor cultural, estivessem melhor instalados, sobretudo no caso da Fototeca, e, nos dois casos, que tivessem a possibilidade de recrutar pessoal técnico mais qualificado e estável, para permitir uma eficaz actuação e atingir um público de utilizadores mais amplo.

Outro problema comparável, mas mais grave ainda por não existir actualmente nenhuma solução, diz respeito aos Arquivos do Centro de Estudos Geográficos. Ao longo de 65 anos de funcionamento, este acumulou grande quantidade de documentos de diversa ordem (correspondência, contas, relatórios, etc.). O seu volume crescente entrou cedo em concorrência espacial com a necessidade de libertar espaços para assegurar, pelo menos, um cantinho de mesa a cada um dos numerosos colaboradores, que se acotovelam nos exíguos gabinetes, em difíceis condições de trabalho. De modo que se decidiu empacotar grande parte dos Arquivos e mandá-los para longínquas arrecadações. Quer dizer, torná-los, na prática, inacessíveis, exactamente na altura em que se multiplicam os pedidos de consulta por parte de investigadores de várias nacionalidades, interessados pelo passado da Geografia.

Nestes Arquivos, por agora ocultos, encontra-se toda a história do Centro de Estudos Geográficos e parte da história profissional do seu promotor e antigo Director. Quase nunca consegui ter acesso a eles durante os anos de tratamento prévio do Espólio, quando me teriam sido tão úteis para resolver dúvidas. Mas, em compensação, a parte dos documentos conservados em nossa casa tornou-se 
cada vez mais acessível, à medida que a sua arrumação nos permitia descobrir peças preciosas, às vezes esquecidas pelo próprio autor. Alguns destes documentos foram já aproveitados recentemente por mim, em várias publicações (Ribeiro, no prelo; Daveau, 2005, 2007a e b). Muitos outros, agora já repertoriados e arrumados, interessam um amplo leque de investigadores. A recente multiplicação de publicações de memórias, biografias e repertórios de correspondência, referentes ao século passado, mostra bem o crescente interesse por aquela categoria de documentos.

O projecto de criar um pequeno Museu caseiro, no Centro de Estudos Geográficos, com exposições temporárias sobre os antigos colaboradores e a sua diversificada obra, seria uma resposta feliz, ainda que parcial, aos numerosos pedidos de consulta. À semelhança do que se realiza já na Mapoteca, relativamente ao passado da Cartografia portuguesa, tal Museu permitiria que os colaboradores mais jovens e os alunos de Geografia e matérias afins conhecessem a história da ciência que praticam. Nele entrariam com naturalidade as famosas candeias, que gerações de alunos ofereceram simbolicamente a Orlando Ribeiro no fim das excursões, para lhe agradecer "a luz" que tinha derramado no espírito deles, bem como outras lembranças do pequeno grupo de investigadores entusiastas, que fizeram crescer o Centro.

Criado em 1943, este ficou apenso, em 1960, à Faculdade de Letras de Lisboa, grande escola sobretudo destinada a formar docentes para o ensino secundário, passando então a funcionar em parceria com ela. Esta dupla especificidade não o vocacionou para a conservação documental, nem para a disponibilização eficaz do seu Arquivo a um público diversificado. Não tem pessoal suficientemente numeroso e estável, e provido de formação adequada. Nem seria, aliás, desejável que o Centro de Estudos Geográficos tivesse regras de funcionamento demasiado rígidas e permanentes. Virado para acções de formação e de pesquisa rápidas e evolutivas, ele está destinado a progredir e não a conservar e a gerir de modo sustentado uma abundante documentação.

Ora, acontece que um dos maiores organismos culturais do país, a Biblioteca Nacional de Portugal, se encontra fisicamente implantada a dois passos do Centro de Estudos Geográficos e está vocacionada para isso. Há 25 anos foi aí criada uma Área de Espólios, hoje chamada Arquivo de Cultura Portuguesa Contemporânea. Uma recente exposição de grande qualidade, As Mãos da Escrita, patente de Maio a Agosto de 2007, permitiu apreciar a riqueza e a variedade dos espólios de autores portugueses já ali arquivados, bem como o profissionalismo do tratamento que lhes é aplicado (Duarte, 2007). Decidiu-se portanto, depois de demorada e recíproca ponderação, que o Centro de Estudos Geográficos, legítimo proprietário do legado do Professor Orlando Ribeiro, confiaria ao Arquivo de Cultura Portuguesa Contemporânea, em regime de depósito, a gestão da parte do Espólio que, simultaneamente, interessa a um público mais largo e exige maiores competências de conservação e manutenção. Irão ser aí geridos tanto os Manuscritos (inéditos ou já publicados) e a Correspondência pessoal, como uma série de Inquéritos, realizados no fim 
dos anos 30 do século XX, e uma parte muito valiosa do Espólio, os 63 Cadernos de Campo (fig. 5).

Que a gestão dos Manuscritos de Orlando Ribeiro tenha de ser confiada ao Arquivo de Cultura Portuguesa Contemporânea resulta também do facto de aquele geógrafo ter sido, além de cientista de nomeada internacional, um dos grandes prosadores portugueses do século XX. Estando já publicada a esmagadora maioria dos seus manuscritos, estes perderam valor significativo no campo da Geografia, mas continuam a interessar a história da cultura portuguesa.

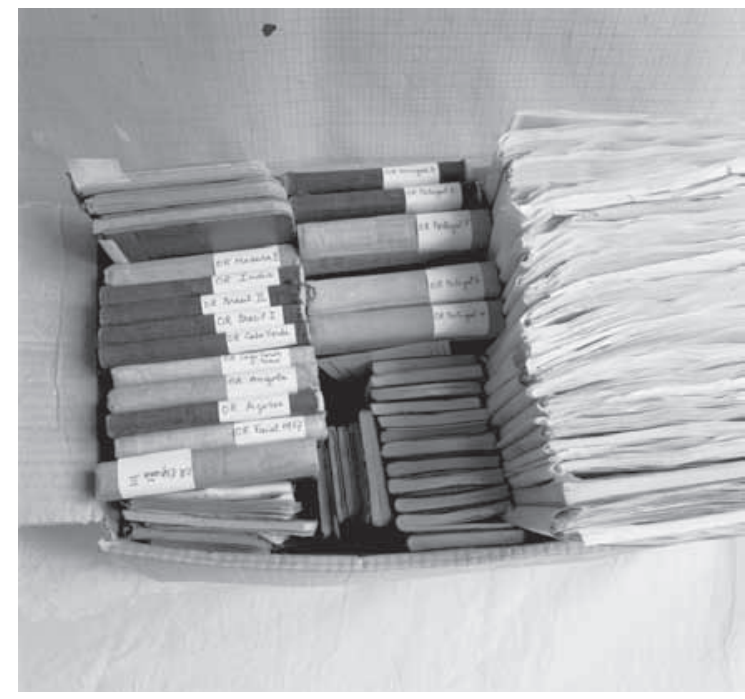

Fig. 5 - Alguns cadernos de campo.

Fig. 5 - Some field note-books.

A Correspondência pessoal levanta um problema específico - o de ser demasiado cedo para se poder colocar parte das cartas à livre consulta dos interessados. Ora, o Arquivo de Cultura Portuguesa Contemporânea aplica as regras internacionais que asseguram a necessária confidencialidade, sem deixar de tornar acessível um conjunto documental importante para o conhecimento da sociedade portuguesa do século XX.

Os Inquéritos exemplificam um modo de reunir documentação, que já se praticava em Portugal no século XVIII. As numerosas respostas, esquecidas num caixote durante muito tempo, precisariam de ser estudadas, para determinar o tipo de correspondentes que as redigiu, bem como a medida em que foram utilizadas por Orlando Ribeiro e colaboradores. As várias edições dos questionários impressos que promoveram as respostas (Ribeiro, 1938 a e b) serviram de orientação metodológica a múltiplos discípulos, directos ou ignorados, em Portugal e no Brasil, e também em Espanha, já que o Inquérito de Geografia Regional 
foi traduzido para espanhol em 1952 e muito utilizado nas inúmeras tesinas que se realizaram nas Universidades do país vizinho.

Completou-se a colecção dos 63 Cadernos de Campo, pela recuperação dos que apareceram a pouco e pouco, misturados com os manuscritos progressivamente ordenados. É, talvez, a parte mais valiosa de todo o Espólio, por reunir uma documentação excepcional sobre Portugal e numerosos outros países. As notas e os elucidativos desenhos foram rabiscados diariamente, no próprio campo de investigação. Testemunham, sem qualquer retoque interpretativo, do que viu e ouviu Orlando Ribeiro nas suas andanças através do mundo. Alguns destes apontamentos constituem o único testemunho que ficou da vida passada de uma aldeia trasmontana ou de tal e tal lugar do sertão brasileiro, ou do mato angolano. Geógrafos brasileiros disseram-nos, mais de uma vez, que, se os dados anotados sobre o seu país tivessem sido conhecidos há decénios, os progressos da Geografia brasileira teriam sido bem mais rápidos. As fotografias de Orlando Ribeiro, hoje consideradas tão valiosas e já parcialmente publicadas, atingem pleno significado quando confrontadas com as anotações tomadas, na mesma altura, no correspondente caderno de campo.

Como escolher o melhor destino a dar à colecção dos Cadernos de Campo? O problema resultava tanto da fragilidade deste tipo de documento como da dificuldade da sua utilização. A primeira destas dificuldades pode, felizmente, ser ultrapassada com facilidade, através da digitalização, capaz de substituir, em larga medida, a consulta directa do documento. Quanto ao segundo problema, Orlando Ribeiro encarregou, em 1975-77 duas boas alunas, promovidas a monitoras do curso de Geografia, de realizar os índices locativos e temáticos dos seus cadernos dedicados ao estudo de Portugal. Os verbetes elaborados por Maria João Alcoforado e Ana Ramos Pereira facilitam já imenso a procura de dados sobre Portugal. É de encarar a passagem destes verbetes para suporte informático, o que facilitaria o seu uso.

Relativamente aos cadernos consagrados ao estudo de outros países, a indexação não foi realizada em vida do autor. Mas pode-se já consultar, no Sítio Orlando Ribeiro, o catálogo de todos os cadernos, com indicação dos países e regiões descritos. Por outro lado, foi realizada a transcrição em suporte informático de todos eles. Foi uma tarefa difícil, uma vez que os apontamentos foram, quase sempre, directamente escritos no campo, em cima do joelho, a tinta ou a lápis, usando abreviaturas e línguas variadas, às vezes misturadas: um verdadeiro quebra-cabeças para o leitor. Por isso mesmo, a consulta prévia da transcrição, ainda que imperfeita, constitui uma grande ajuda para o utilizador. Ele localizará assim com facilidade os temas e os lugares que lhe interessam, antes de passar à fase de decifração, por conta própria, do manuscrito digitalizado e, em caso de necessidade, do próprio original. Ficando a conservação dos originais confiada ao Arquivo de Cultura Portuguesa Contemporânea, uma cópia ficará disponível em suporte informático, com a respectiva transcrição, tanto aí, como no Centro de Estudos Geográficos, segundo modalidades da consulta a definir pelos respectivos responsáveis. 


\section{OBRAS CITADAS:}

Daveau S (2007a) Planeamento e difusão das obras de Orlando Ribeiro. Geophilia - o Sentir e os Sentidos da Geografia, CEG, Lisboa: 171-183.

Daveau S (2007b) La Géographie ça peut survivre à la guerre, correspondance entre Jean Gottmann et Orlando Ribeiro. Finisterra - Revista Portuguesa de Geografia, XLII (83): 5-21.

Daveau S (2005) Leite de Vasconcellos, Orlando Ribeiro e a casa rural portuguesa. In Orlando Ribeiro, Formas construtivas elementares, Museu do Canteiro, Alcains: 49-52.

Daveau S (2004) Um novo Sítio na Internet, dedicado a Orlando Ribeiro. Finisterra. Revista Portuguesa de Geografia, XXXIX (78): 123-124.

Daveau S, Feijão M J, Barata P J S (2002) O Espólio científico do Professor Orlando Ribeiro, Finisterra. Revista Portuguesa de Geografia, XXXVII (73): 133-137.

Duarte L F (org.) (2007) As mãos da escrita. Catálogo e estudos de casos. BNP, Lisboa.

Ribeiro O (1938a) Inquérito do habitat rural. IAC, Coimbra, 2. ${ }^{a}$ ed. 1939.

Ribeiro O (1938b) Inquérito de Geografia Regional. IAC, Coimbra, 2. a ed. 1947; ed. policopiada, 1961; tradução espanhola, 1952.

Ribeiro O (no prelo) Leite de Vasconcellos na História e na Lenda. O Arqueólogo Português, Lisboa.

\section{LA DONATION SCIENTIFIQUE D'ORLANDO RIBEIRO}

\section{NATURE ET SIGNIFICATION DE LA DONATION}

Ayant créé en 1943 le Centre d'Études Géographiques de Lisbonne, Orlando Ribeiro conçut cet organisme de recherche comme largement ouvert à tous les intéressés. Quant aux documents qu'il conservait chez lui, il les destinait à rejoindre le Centre dès qu'il n'en aurait plus besoin pour ses recherches. Dès 1965, il fit établir le catalogue de sa bibliothèque, afin de faciliter sa future insertion dans celle du Centre. Ses photos et ses cartes furent, dès l'origine, gérées par celui-ci. En 1983, il rédigea un testament, où il indiquait en détail le destin souhaité pour sa bibliothèque et pour ses notes et manuscrits encore inédits. Il chargea alors son fils António et moi-même d'assurer la réalisation de sa volonté. Il me fallut dix ans, après sa mort en 1997, pour mener à bien la préparation et le catalogage du legs, ainsi que pour trouver les meilleures solutions de conservation et d'accès à celui-ci.

\section{LA PRÉPARATION DU MATÉRIEL}

On se reportera à l'article publié en 2002 dans le n. ${ }^{\circ} 73$ de Finisterra, pour y trouver un extrait du testament et les normes qui furent appliquées à l'inventaire et au catalogue des éléments du legs conservés dans la maison de Vale de Lobos. Cet énorme travail fut rendu possible par les subventions successivement accordées par la Fundação para a Ciência e Tecnologia et par la Fondation Gulbenkian, mais aussi par l'aide enthousiaste et persistante de parents et amis, et par la compétence dévouée des divers bibliothécaires qui y participèrent, sous la direction de Maria Joaquina Feijão. 
En 2004, la préparation du matériel nous parut suffisamment avancée pour permettre la diffusion sur Internet d'une édition provisoire du Site Orlando Ribeiro, comportant la moitié environ du catalogue de la Bibliothèque scientifique personnelle, ainsi que la première version d'autres rubriques, ainsi soumises à l'épreuve d'un jugement public. L'expérience se révéla positive, de telle sorte que l'édition actuelle, considérée comme pratiquement définitive, maintient, tout en l'enrichissant, l'organisation qui avait été donnée à la première version.

\section{LE SITE INTERNET ORLANDO RIBEIRO}

La nouvelle édition a été surtout enrichie par l'inclusion du catalogue complet de la Bibliothèque scientifique. Les principales rubriques sont les suivantes:

- Une Biobibliographie, qui situe les œuvres principales de l'auteur dans le cadre des cinq périodes qui ont scandé sa vie: la Jeunesse, la Formation, Paris et le Congrès Géographique International de Lisbonne, le Professeur et le Chercheur, le Retraité.

- La Bibliographie Scientifique de l'auteur, riche de 413 publications, soigneusement ordonnées et annotées.

- Une liste d'études sur sa vie et son cuvre (Bibliographie dite passive).

- L'évocation d'une partie de ses voyages, à partir d'une sélection de ses photographies.

- La liste des lieux décrits dans ses 63 carnets de terrain.

- L'indication des séries de photos qui furent publiées ou montrées en expositions.

- Finalement, l'important catalogue de la Bibliothèque Scientifique personnelle, riche de 13324 numéros. Elle s'est constituée peu à peu, de 1929 à 2004, étant enrichie par mes propres apports à partir de 1965. Le système de cotation permet de reconstituer l'organisation spatiale qu'avait la Bibliothèque originelle. L'étude des dédicaces fournit des éléments sur les échanges scientifiques qui l'ont alimentée, cependant que les notes de lecture illustrent l'usage qui en fut fait.

\section{CONSERVATION ET ACCÈS À LA DONATION}

Comment assurer à la fois bonne conservation et accès efficace à l'abondant matériel scientifique qui fut classé de 1997 à 2005? Ce n'est que très récemment que des solutions viables ont été trouvées. En effet, l'idée originelle du donateur, d'utiliser son ancien bureau comme lieu de conservation et de lecture, était inapplicable. Un Centre de recherches n'a pas pour vocation la conservation d'une documentation abondante, complexe et soumise, en outre, à des règles plus ou moins restrictives d'accès. La Bibliothèque de la Faculté des Lettres, organisée en libre accès, ne peut conserver des tirés à part annotés et dédicacés. On a donc décidé, finalement, la division en trois parties du legs:

- Le Centre d'Études Géographiques conservera e gèrera les éléments déjà insérés dans ses riches Bibliothèque, Photothèque et Mapothèque. Il est souhaitable qu'il organise en outre ses propres Archives et un petit Musée, évoquant tant ses origines que l'œuvre des chercheurs qui y ont travaillé. 
- La Bibliothèque scientifique d'Orlando Ribeiro va être installée, comme celles qui ont été léguées par d'autres anciens Professeurs de la Faculté des Lettres, dans des salles annexes de la Bibliothèque principale de celle-ci, avec des normes et des lieux de lecture adaptés aux caractéristiques des donations.

- Le service des Archives de la Culture Portugaise Contemporaine, de la Bibliothèque Nationale du Portugal, accepte de recevoir en dépôt l'ensemble des manuscrits d'Orlando Ribeiro et, en particulier, sa correspondance personnelle, ainsi que les précieux carnets de terrain, en assurant à la fois la sûreté de leur conservation et les normes d'un accès commode et régulier.

\section{THE SCIENTIFIC LEGACY OF ORLANDO RIBEIRO}

\section{CHARACTERISTICS AND MEANING OF THE LEGACY}

The Centro de Estudos Geográficos of the University of Lisbon was created in 1943. Orlando Ribeiro originally conceived it as a Research Centre open to whoever shared an interest in the discipline. The documents that he used in his research at home returned to the Centre after he no longer needed them. As early as 1965, he had his own library catalogued so that it would later be turned over to the Centre. His photographs and maps were preserved in the Centre's Photographic and Cartographic Archives. His will and testament, written in 1983, specified his final intentions with respect to the destiny of his Library and his unpublished papers and notes.

\section{PREPARING THE LEGACY}

A full ten years were spent ordering Orlando Ribeiro's Legacy and seeking the best way to preserve it and put it to the best possible use. A previous paper published in Finisterra $(73,2002)$ describes the inventory and cataloguing methods that were used. This complex endeavour was made possible thanks to funding by the Foundation for Science and Technology and the Foundation Gulbenkian, the skills of several librarians and the help of friends and relatives.

By 2004, the inventory work was sufficiently on its way to allow for the creation of a provisional Web Site. It contains about one half of the entire catalogue of Orlando Ribeiro's Scientific Library, as well as an early draft of other items. This made it possible to obtain feedback from a number of potential users, which was good enough to convince us to maintain the same arrangement in the definitive edition.

\section{THE ORLANDO RIBEIRO WEB SITE}

The Orlando Ribeiro Web Site contains:

- A Biobibliography, divided into five different periods; Youth, Studies, Paris and the International Geographical Congress in Lisbon, Teaching and Research, Retirement.

- The Scientific Bibliography, including 413 ordered and annotated items. 
- A significant part of his journeys through the World, illustrated with his own photographs.

- A listing of his 63 field note-books.

- The publication and exhibition of his photographs.

- Finally, the catalogue of his Scientific Library, rich of 13324 items.

\section{PRESERVING AND USING THE LEGACY}

By 2005, even though Orlando Ribeiro's Legacy had already been largely catalogued and prepared, a decision was yet to be taken as to its ultimate fate. A Research Centre is not well-prepared to preserving a complex and ample body of documentation and to organizing its use by the public. A freeadmittance Library, on the other hand, is not well-suited to keeping and preserving such diverse materials as notes and dedications.

Responsibility for those parts of Orlando Ribeiro's Legacy that are included in the Library and in the Photographic and Cartographic Archives of the Centro de Estudos Geográficos will remain with this Centre, which in turn shall set up an Archive office and a small Museum.

The Orlando Ribeiro Scientific Library will be located in a room adjacent to, but distinct from, the General Library of the Faculty of Arts, and will have its own set of regulations.

The manuscripts, letters and precious field note-books will be entrusted to the Contemporary Portuguese Cultural Archive of the Portuguese National Library. 